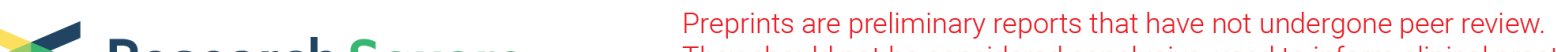

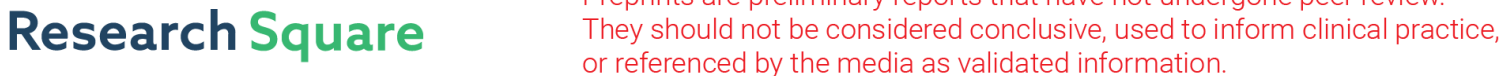

\section{Deficiency of Klc2 induces Low-Frequency Sensorineural Hearing Loss in C57BL/6J Mice and Human}

\section{Xiaolong Fu}

Southeast University - Sipailou Campus: Southeast University

\section{Yachun An}

Shandong University

Hongyang Wang

Chinese PLA General Hospital

Peipei Li

Shandong University

Jing Lin

Rutgers University: Rutgers The State University of New Jersey

Jia Yuan

Southeast University - Sipailou Campus: Southeast University

\section{Rongyu Yue}

Shandong University Affiliated Hospital: Shandong Provincial Hospital

Yecheng Jin

Shandong University

Jiangang Gao ( $\nabla$ jggao@sdfmu.edu.cn )

Shandong First Medical University

\section{Renjie Chai}

Southeast University - Sipailou Campus: Southeast University https://orcid.org/0000-0002-3885-543X

\section{Research Article}

Keywords: hair cells (HCs), Klc2 (kinesin light chain 2)

Posted Date: March 11th, 2021

DOI: https://doi.org/10.21203/rs.3.rs-277106/v1

License: (c) (1) This work is licensed under a Creative Commons Attribution 4.0 International License.

Read Full License 


\section{Abstract}

The transport system in cochlear hair cells (HCs) is important for their function, and the kinesin family of proteins transport numerous cellular cargos via the microtubule network in the cytoplasm. Here, we found that Klc2 (kinesin light chain 2), the light chain of kinesin-1 that mediates cargo binding and regulates kinesin-1 motility, is essential for cochlear function. We generated mice lacking Klc2, and they suffered from low-frequency hearing loss as early as 1 month of age. We demonstrated that deficiency of Klc2 resulted in abnormal transport of mitochondria and the down-regulation of the GABAA receptor family. In addition, Whole genome sequencing(WGS) of patient showed $K L C 2$ was related to low-frequency hearing in human. Hence, to explore therapeutic approaches, we developed adeno-associated virus containing the KIc2 wide-type cDNA sequence, and KIc2-null mice delivered virus showed apparent recovery, including decreased ABR threshold and reduced Out Hair Cell $(\mathrm{OHC})$ loss. In summary, we show that the kinesin transport system plays an indispensable and special role in cochlear $\mathrm{HC}$ function in mice and human, and that mitochondrial localization is essential for $\mathrm{HC}$ survival.

\section{Introduction}

According to the WHO in 2020, over $5 \%$ of the world's population - about 466 million people - have disabling hearing loss, and this number is expected to increase to over 900 million by 2050 . Hearing loss affects every aspect of a person's life. Sensorineural hearing loss can be congenital or acquired and results from damage to the organ of Corti caused by genetic factors, drugs, age, noise exposure, etc. ${ }^{1-7}$. As the auditory sensory cells, $\mathrm{HCs}$ in the cochlea play a role in converting mechanical signals into electrical signals, and proper cargo transport is indispensable for these cells' development and function ${ }^{8}$. Myosin motor proteins in cochlear HCs have been widely studied because they transport the components of the actin assembly machinery that are necessary for regulating stereocilia length. For instance, Myo15a binds to whirlin and localizes it to stereocilia tips ${ }^{9-12}$, and Myo7a transports twinfilin-2 and is related to stereocilia length ${ }^{13-16}$. In eukaryotes, the place where a substance is produced is not necessarily where it is needed to function, and thus transport motors are needed to maintain the cell's activities $^{17}$.

Kinesin- 1 is one kind of motor proteins that mediates cargo transport toward the plus-ends of microtubules using the energy from the hydrolysis of ATP, and dysfunction of kinesin- 1 is associated with numerous diseases including Alzheimer's disease, cancers, and diabetes ${ }^{18-20}$. Kinesin-1 consists of two kinesin heavy chains (KHCs) that are widely believed to bind to microtubules and to hydrolyze ATP and two kinesin light chains (KLCs) that mediate cargo binding and regulate kinesin-1 motility. Klc2, one of the KLCs, is a widely expressed molecular motor ${ }^{21}$ that mediates the transport of numerous cargos, including intracellular organelles, synaptic vesicles, and microtubule dimers. Batut discovered that Klc2 interacts with Smad2 and transports it to the nucleus where it triggers downstream signaling pathways ${ }^{22}$, and huntingtin is anterogradely transported in axons by means of the binding between HAP1 and KLCs ${ }^{23}$. Additionally, a study showed that GSK-3 phosphorylates KLC2 in order to regulate AMPAR trafficking by 
the kinesin system ${ }^{24}$. Thus, Klc2-mediated cargo transport plays an important role in various physiological activities and ensures the normal activities and function of cells.

To investigate whether the Klc2-mediated transport system plays an important role in the auditory system, KIc2-null mice were generated using CRISPR/Cas9 technology. We found that KIc2 is essential for the function of HCs, but not for SGN (spiral ganglion) or StV (stria vascularis) function. KIc2-null mice showed low-frequency sensorineural hearing loss at 1 month of age, and they were completely deaf at 8 months of age. In addition, KIc2-null mice showed normal gross morphology, suggesting that the Klc2mediated transport system is only essential in the OHCs of the cochlea. Strikingly, we found that mitochondrial distribution was altered in $\mathrm{OHCs}$, indicating that mitochondrial transport mediated by Klc2 is vital for the function and survival of OHCs. Furthermore, a 21-year-old male with an indel variant c.1444-8_1444-6delTCC in KLC2 gene (NM_001134775.1) was screened out by WGS and he showed lowfrequency hearing impairment, which is corresponding to the phenotype of KIc2-null mice. It proved that $K I C 2$ is necessary for both mice and human. Morever, we designed and packaged Adeno-associated virus (AAV) to cure and recover the hearing impairment in KIc2-null mice and achieved a curative effect. Altogether, our work shows for the first time that the transport of mitochondria mediated by kinesin-1 in auditory $\mathrm{OHCs}$ relies on $\mathrm{Klc2}$, and deficiency of $\mathrm{Klc} 2$ results in $\mathrm{OHC}$ death and hearing loss.

\section{Material And Methods:}

\section{Animal models}

KIc2-null mice were generated by CRISPR/Cas9 technology in the C57BL/6J background. Two different sgRNAs (sgRNA1: GCC CAT GAC TAA CGG ACA CC, sgRNA2: CAG TTT GGC CCA CTC ACT GCT GG, designed by benchling.com) were cloned into the plasmid pX330 (Addgene ID: \#42230) digested with Bbsl (NEB: \#R0539V). These two plasmid mixtures were co-injected into the zygote's nucleus after incubating for two hours at $37^{\circ} \mathrm{C}$ and $5 \% \mathrm{CO}_{2}$. The zygotes were then transferred to the oviducts of pseudopregnant $C D 1$ female mice. The newborns' genomic DNA was extracted from the tails and amplified by PCR using three sets of primers (F1: 5'-AAT ACA GGG TCC TAG ACT CCA AC-3'; R1: 5'-TTA TCC TCC TCC ACC ATG AAA G -3'; R2: 5'-CCT AGC CAT CAC TTT GCC TAT A-3').

\section{Auditory brainstem responses (ABRs)}

ABRs were measured as described previously ${ }^{25}$. Mice were anesthetized by pentobarbital sodium (50 $\mathrm{mg} / \mathrm{kg}$ body weight) before the experiments and kept on a heating pad to maintain the body temperature at $37^{\circ} \mathrm{C}$. All recordings were completed in a custom-made soundproof acoustic chamber using a TuckerDavis Technologies System (TDT, USA) workstation running the SigGen32 software (TDT, USA). Subcutaneous platinum needle electrodes were placed at the vertex of the skull, behind the ear, and underneath the back. Auditory thresholds ( $\mathrm{dB} S \mathrm{SP}$ ) were defined as the lowest sound intensity sufficient to clearly elicit the first wave response. 


\section{Scanning electron microscopy}

Mice were sacrificed and their cochleae were quickly removed and fixed in $2.5 \%$ glutaraldehyde. After decalcification, the basilar membranes were isolated from the cochlea and divided into the apical, middle, and basal turns. The samples were subsequently treated with $1 \%$ osmium tetroxide and $1 \%$ tannic acid, dehydrated through an ethanol gradient, dried with a critical point drier, and finally observed under a JEOL 7000 field emission gun scanning electron microscope after being sputter-coated with a layer of gold.

\section{Transmission electron microscopy}

Cochleae were dissected and fixed in $2.5 \%$ glutaraldehyde followed by decalcification in $10 \%$ EDTA. After dissection and segmentation, the basilar membranes were fixed with $1 \%$ osmium tetroxide and then dehydrated through an ethanol gradient and embedded in Epon-812. Ultrathin sections were cut with a diamond knife on an ultramicrotome (RMC, Powertome- $\mathrm{XL}$ ) and were observed under a transmission electron microscope (Thermo, FEI Tecnai G2 F20) after uranyl acetate and lead citrate staining.

\section{Protein extraction and western blot}

Mice were sacrificed and their cochleae were dissected and homogenized in ice-cold cell lysis buffer (10 $\mathrm{mM}$ Tris, $\mathrm{pH}=7.4,1 \%$ Triton X-100, $150 \mathrm{mM} \mathrm{NaCl}, 1 \mathrm{mM}$ EDTA, and $0.2 \mathrm{mM} \mathrm{PMSF}$ ) and then lysed for 30 min on ice and centrifuged at $10,000 \times g$ at $4^{\circ} \mathrm{C}$ for $30 \mathrm{~min}$. The supernatant was transferred to a clean centrifuge tube and the protein concentration was quantified with a BCA kit. Samples were mixed with $5 \times$ loading buffer and heated to $100^{\circ} \mathrm{C}$ for $5 \mathrm{~min}$. Equal amounts of each sample were separated by electrophoresis on $12 \%$ sodium dodecyl sulfate-polyacrylamide gels and transferred onto PVDF membranes. The membranes were blocked with $5 \%$ milk in TBST for $1 \mathrm{~h}$ at room temperature and then incubated with primary antibodies in BSA solution at $4^{\circ} \mathrm{C}$ overnight. After washing with TBST, the PVDF membranes were incubated with an HRP-conjugated secondary antibody at room temperature for $1 \mathrm{~h}$. After washing with TBST, the bands were detected with an ECL Western blot kit. The following antibodies were used: anti-KIc2 (Proteintech, 17668-1-AP), anti-Myh14 (CST, 8189P), anti-Gapdh (Boster, BM1623).

\section{RNA extraction and quantitative real time-polymerase chain reaction (q-PCR)}

Total RNA was extracted using Trizol reagent (Ambion, 262304) following the manufacturer's protocol. The cDNAs were synthesized and q-PCR was performed with a $10 \mu \mathrm{l}$ mixture containing $5 \mu \mathrm{l}$ SYBR Green qPCR Mix (SparkJade AH0104), $0.2 \mu \mathrm{l}$ primer F, $0.2 \mu$ primer R, $1 \mu \mathrm{l}$ cDNA template (after dilution), and $3.6 \mu \mathrm{lddH_{2 }}$ O. All procedures were performed in triplicate, and the relative expression was calculated using the 2- $\Delta \Delta \mathrm{CT}$ method. The following primers were used: KIc1 (F: 5'-AGC GGG AGT TTG GAT CTG TG-3'; R: 5'-AGC CAC TCT CTG CTT ACG TGA-3'), KIC2 (F: 5'-AGA AGC TGA GTC AGG ACG AGA-3'; R: 5'-GAT GGC 
TTG ATA ATG CCA GGA T-3'), KIc3 (F: 5'-CCC AAG AGA ACA CAT GGC TTC-3'; R: 5'- GCG GGT CAT ACT GCC TCA G-3'), KIC4 (F: 5'-GTA CGG CAA ACG CGG TAA ATA-3'; R: 5'-GCC CTG GTT TTG ACA TAG GAG G$\left.3^{\prime}\right)$.

\section{Immunohistochemistry}

Cochleae were fixed in $4 \%$ paraformaldehyde in PBS overnight at $4^{\circ} \mathrm{C}$, and the basilar membranes were isolated and divided into three sections after decalcification. Samples were then permeabilized in $0.02 \%$ Triton X-100 and washed three times (10 min each time). After blocking in 10\% goat serum in PBS, the basilar membranes were incubated with the primary antibody at $4^{\circ} \mathrm{C}$ overnight.

The basilar membranes were then washed three times with PBS and incubated with fluorescenceconjugated secondary antibody diluted in PBS for $1 \mathrm{~h}$. F-actin filaments were detected with FITC or TRITC-conjugated phalloidin, and nuclei were stained with DAPI. Samples were imaged using Zeiss LSM780 and Leica confocal microscopes. The following antibodies were used: anti-Myosin7a (Proteus Biosciences, 25-6790), anti-parvalbumin (Sigma, P3088), anti-spectrin (Sigma, mab1622), anti-caspase3 (CST, 9661S), anti-Lc3b(CST,2775S), anti-prestin (sc-22692), anti-3NT (Abcam, ab110282), anti-4HNE (Abcam, ab46545), anti-Kcnma1 (Alomone, APC-021), anti-HAtag (CST, 3724S).

\section{AAV preparation and round window injection}

The AAV was created using triple transfection of HEK293T cells and extracted by iodixanol gradient purification. Briefly, pAAV-CAG-KIc2-HA, pHelper, and pANC80L65 were obtained from a kit (OMEGA, D6950-01) and co-transfected into HEK293T cells. Culture medium and cells were collected after $72 \mathrm{~h}$ and chloroform was added. After centrifugation, the supernatant was precipitated first with $1.0 \mathrm{M} \mathrm{NaCl}$ and then with $10 \%$ PEG 8000 , and the precipitate was resuspended with PBS and treated with benzonase. The iodixanol gradient ( $8 \mathrm{~mL}$ of $15 \%$ iodixanol, $5.5 \mathrm{~mL}$ of $25 \%$ iodixanol, $5 \mathrm{~mL}$ of $40 \%$ iodixanol, and 4.5 $\mathrm{mL}$ of $60 \%$ iodixanol) was prepared, and the crude lysate was layered on top of it. Then centrifuged at $350,000 \mathrm{~g}$ for $90 \mathrm{~min}$ at $10^{\circ} \mathrm{C}$. AAV was enriched in the $40 \%$ layer after ultracentrifugation. The buffer was exchanged to remove the iodixanol, and the purified virus was concentrated. Genomic DNA of postnatal day (P)2 mice was extracted and used for genotyping. Lively KIc2-null pups were selected for injection. After anesthetization by low temperature, the mice were put onto an ice box and a post-auricular incision was made under a microscope to expose the round window for the injection. About $1.5 \mu$ l of AAV solution was injected using a glass microelectrode. Any mice with damaged cochleae were excluded from subsequent analyses.

\section{Statistical analysis}

Data are expressed as the mean \pm SD from at least three independent experiments. Significant differences were determined by two-tailed Student's t-test in Graphpad Prism 7, and p-values $<0.05$ were 
considered statistically significant.

\section{Results}

Knock out ofKIc2by CRISPR/Cas9 in C57BL/6J mice

Kinesin-mediated cargo transport has always been a research hotspot, but this has mainly focused on neurons ${ }^{26-28}$, and little research on such transport in the auditory system has been performed. The light chains of kinesins play an important role in the transport processes as they can be connected to different kinds of cargo ${ }^{22-24}$. Here, we explored whether KIc2 plays a role in the auditory system. First, we used western blot to determine the Klc2 expression pattern in wild-type (WT) mice (Fig. 1A), and we found that $\mathrm{Klc2}$ is widely expressed in various organs. Moreover, the expression level of Klc2 in the cochlea is relatively high, indicating that it might play an essential role in the auditory system. The q-PCR results showed that the cochleae had their highest expression of Klc2 at P14 (Fig. 1B), which is when the development of the organ of Corti is nearly complete. This suggested that Klc2 is related to the maintenance of hearing function. To investigate the specific function of Klc2 in the cochlea, we used CRISPR/Cas9 technology to generate KIc2-null mice. Two specific sgRNAs were designed to target $K / c 2$ between intron 2 and intron 11, which abolishes the whole coding sequence of Klc2. Genomic DNA from mouse pups was extracted for PCR genotyping using the primers shown in Fig. 1C. Potential off-target sites were predicted by an online database (https://cm.jefferson.edu/Off-Spotter/), and every potential off-target site was amplified by PCR followed by sequencing. No off-target sites were found. In the KIc2null mice, Klc2 could not be detected in the cochlea by q-PCR (Fig. 1D) or by western blot (Fig. 1E), indicating that Klc2 was successfully knocked out.

Klc2 is required for the normal function of the cochlea

KIc2-null mice had a normal gross morphology and did not show any apparent defects compared with their WT littermates. We analyzed the auditory functions of KIc2-null mice as they aged, and at P40 the KIc2-null mice showed significant low-frequency hearing loss (Fig. 2A) while high-frequency hearing was not affected. We performed H\&E staining to explore the cochlear morphology of Klc2-null mice (Fig. 2C). The OHCs were lost, but the inner HCs (IHCs), the SGN, and the StV were normal compared to WT mice, which indicated that $\mathrm{OHC}$ death was the primary reason for the hearing loss seen in KIc2-null mice. Whole-mount staining of Myo7a and phalloidin, two HC-specific markers, showed that KIc2-null mice lost massive OHCs from the apical region at P40 (Fig. 2B and 2D). Immunofluorescence staining also performed on WT and Klc2-null mice basilar membrane in different time points before P40, and we confirmed that OHCs began to lose at P3O in KIc2-null mice. Thereafter massive cell loss occurred with further age, and the OHCs were nearly completely absent at 8 months of age and hearing was almost completely lost (Figure S1A-C). We further checked the morphology of the stereocilia using SEM (Fig. 3), and no abnormalities were seen in the remaining OHCs, indicating that Klc2 functions mainly in the cell body of OHCs. In addition, we checked the expression of other light chains of kinesin (KIc1, Klc3, and KIc4), and q-PCR of P30 WT and KIc2-null mice showed no significant changes in these three genes 
(Figure S1D), suggesting that the role of Klc2 in the cochlea is not related to these three genes. In conclusion, Klc2 appears to be essential for the survival of OHCs, and loss of OHCs is the reason behind the hearing loss in KIc2-null mice.

\section{Klc2 Binds To Cuticular Plate-related Proteins}

Loss of Klc2 impairs cochlear HC function but does not affect the SGN and StV, so we sought to determine the role that Klc2 plays in $\mathrm{HC}$ survival. Klc2 is the light chain of kinesin-1, and it connects to the kinesin heavy chains and to the cargo molecules.

We therefore carried out a co-immunoprecipitation from P30 mouse cochleae using Klc2-specific antibody, followed by protein identification by peptide mass spectrometry (CoIP-MS), to identify the possible cargos that are essential for auditory function in OHCs.

Approximately 916 proteins were identified from the IgG samples and 663 proteins from the Klc2 antibody samples, and 128 proteins were left in the Klc2 antibody samples when the 535 common proteins were subtracted (Figure S2A). As expected, some known Klc2-binding proteins like Kinh and Kif5c were included in these 128 proteins. Classification comparison was performed, and we identified a set of proteins that are reported to be localized to the cuticular plate (Tpm3, Myosin6, Sptb2, and Sptn1) 29-31. Co-IP were performed to further validate the CoIP-MS result. We chose Myh14, a protein related to noise-induced hearing loss that we have reported on previously, and it showed strong binding affinity for Klc2 in the ColP-MS data (Figure S2B) ${ }^{32}$. However, immunofluorescence of P30 WT and Klc2-null mice did not show any abnormal morphological structures of spectrin (Figure S2C), which is a well-known marker of the cuticular plate. These results demonstrated that although Klc2 binds to the cuticular plate, it does not affect its morphology.

Knock out ofKlc2disrupts the distribution of mitochondria

TEM was performed to check the subcellular structure of HCs in WT and KIc2-null mice at P30, which was when the hearing loss phenotype first appeared. We found that the structure of the cuticular plate was normal, further indicating that it was not the primary reason for $\mathrm{HC}$ death. However, we found that the distribution of mitochondria was affected in the HCs of the cochlea after careful examination. Normally, mitochondria are located along the plasma membrane, under the cuticular plate, and around the nucleus to provide the energy required for $\mathrm{OHC}$ activity ${ }^{33}$, but the mitochondria were concentrated in the center of the cytoplasm of the OHCs from KIc2-null mice (Fig. 4A-C). It is noteworthy that the OHC nuclei of KIc2null mice were normal at P30 (Fig. 4B), suggesting that there was still a period of time before these cells died, and the abnormal mitochondrial localization might be the primary factor that triggers a series of events that lead to $\mathrm{HC}$ death. We concluded that deficiency of Klc2 disrupts the mitochondrial transport system, which depends on kinesin and the microtubule network. The disordered mitochondrial transport system might subsequently affect normal mitochondrial function like energy production, apoptosis, autophagy, etc., thus leading to $\mathrm{HC}$ degeneration and hearing loss. Next, to explore the possible cause of 
OHC death, we co-stained parvalbumin with apoptosis marker caspase-3 and autophagy marker Lc3b, respectively. No positive signal for caspase-3 or Lc3b was observed (Figure S3A). The expression pattern of prestin in KIc2-null mice was normal compared to WT mice (Figure S3B), suggesting that the aberrant mitochondrial distribution did not affect the magnification ability of OHCs. It is reported that inaccurate distribution of mitochondria might cause problems with reactive oxygen species (ROS) production ${ }^{34}$, but KIc2-null mice did not show this phenomenon (Figure S3C). Interestingly, a decreased number of BK channels was seen in IHCs (Fig. 4E-F), which might be related to the special BK variant (called the DEC splice variant or MitoBK) that is specifically located in mitochondria ${ }^{35-37}$. In summary, we found that aberrant mitochondrial distribution resulted in $\mathrm{HC}$ degeneration, but this was not related to apoptosis, autophagy, or redox imbalance.

\section{Gabaa Receptor Might Be Associated With The Auditory Phenotype}

To further explore the intracellular changes caused by defective mitochondrial distribution which leads to $\mathrm{HC}$ loss in KIc2-null mice, RNA-seq analysis were performed at P30. We found that 28 genes were upregulated and 366 genes were down-regulated (Fig. 5A). Moreover, 55 genes were classified as "Transporter activity" (Fig. 5B). From the Gene Ontology (GO) analysis, we found that expression of multiple GABAA receptor family genes was decreased (GABAA receptor subunits $\alpha 1, \beta 2, a 3, \delta, a 2$, $a 6$, and $\mathrm{Y1}$ ) in the KIc2-null mice (Fig. 5C and 5D). GABA, as one kind of inhibitory neurotransmitter, interacts with GABA receptors in order to regulate cellular activities. In the inner ear, the olivocochlear efferent system is both cholinergic and GABAergic, and several studies have shown that GABA receptor is essential for cochlear function ${ }^{38-40}$. Liberman constructed a set of mouse models and showed that knockout of three mouse lines ( $a 1, a 2$, and $a 6$ ) did not affect cochlea function ${ }^{39}$. We therefore validated the down-regulated expression of the remaining genes in our RNA-seq results (genes showed in Fig. 5D subtract sunbunits a1, a2, and a6 ) by q-PCR(Fig. 5E). In short, knock out of KIc2 led to the down-regulation of multiple GABAA subunits, which might arise from abnormal mitochondrial localization, and this might be one reason for the disruption of the auditory system.

An indel variant in humanKLC2is associated with low-frequency hearing impairment

A 21-year-old male (case 1707652) complaining bilateral hearing impairment was related to our research, with the onset age of 14 years old. Whole genome sequencing found an indel variant c.1444-8_14446delTCC in KLC2 gene (NM_001134775.1) from the patient. This novel variation was not found in the 1000 Genomes Project, ExAC 65000 exome allele frequency data and 1751 ethnicity-matched controls. No family history was complained (Fig. 6A). Otological examinations battery including pure tone audiometric examination, distortion product otoacoustic emission (DPOAE), ABR, cochlear microphonics (CM), speech recognition score (SRS) performed on him illustrated the typical auditory neuropathy. The audiogram of the proband showed low-frequency affected hearing impaired (Fig. 6B) with damaged SRS ( $20 \%$ and $48 \%$ for the left and right ear, respectively). DPOAE for the proband was normal (Fig. 6C), and 
no waves could be detected in ABR testing bilaterally (Fig. 6D). It is worth mentioning that our mouse model also showed low-frequency hearing loss which replicated phenotype in human exactly.

\section{Therapeutic Approaches Using Aav}

We next explored therapeutic strategies of hearing impairment caused by KIc2 deficiency. AAV has proved to be a safe and effective viral vectors for genetic therapy in the inner ear ${ }^{41}$.Hence, we tested whether AAV containing the whole WT KIc2 cDNA sequence could rescue the deafness phenotype in KIc2-null mice. The synthetic vector Anc80L65 was used to viral packaging. At P2, KIc2-null mice were treated with an AAV solution by round window injection ${ }^{41}$, and saline was injected into littermates as the vehicle control. In addition, we labelled the HA tag and observed high efficiency of infection at P14 (Fig. 7A), and western blot was performed to validate the expression of Klc2. Only the cochlear sample treated with AAV showed a clear band using both anti-HA and anti-Klc2 antibodies (Fig. 7B), indicating that Klc2 was reexpressed only in the cochlea and not in other tissue. We then wanted to know whether re-expressing Klc2 rescues KIc2-null mice from hearing loss. As expected, both the ABR threshold and OHC survival ratio showed an apparent recovery in KIc2-null mice at P40 (Fig. 7C-D), and the mean hearing thresholds at $4 \mathrm{kHz}, 8 \mathrm{kHz}$, and $12 \mathrm{kHz}$ were reduced by about $27 \mathrm{~dB}(\mathrm{p}<0.001), 34 \mathrm{~dB}(\mathrm{p}<0.001)$, and $17 \mathrm{~dB}(\mathrm{p}<0.05)$, respectively. We concluded that Klc2 reexpression decreased $\mathrm{OHC}$ degeneration and prevented hearing loss, and AAV was an effective vector for Klc2 delievery.

\section{Discussion}

In this study, we show that Klc2, one of the light chains of kinesin-1, is vital for the low-frequency hearing both in mice and human. KIc2-null mice generated by CRISPR/Cas9 suffered from low-frequency hearing loss, and we filtered out a patient with defective $K L C 2$ variant also showed similar auditory symptom. Loss of Klc2 leads to the abnormal distribution of mitochondria in mice and thus leads to the death of HCs, and our study is the first to show that improper mitochondrial localization is an important cause of hearing loss.

Most hearing loss families and gene knockout models show that hearing loss occurs first at high frequencies, and many stressors generate high-frequency hearing damage. The unique physiological structures of the cochlea and the biological functions of HCs means that HCs are more delicate in the high-frequency regions, but in our case auditory dysfunction was seen at low frequencies. Hearing dysfunction at low frequencies is not without precedent. Wolfram Syndrome Spectrum Disorder, caused by a WFS1 (DFNA6/14) mutation, leads to low frequency sensorineural hearing impairment ${ }^{42}$, while a protein-truncating mutation in DIAPH1 (DFNA1) results in autosomal-dominant low-frequency deafness ${ }^{43}$; 4 . And we also screened out that a 21-year-old male with abnormal $K L C 2$ gene (an indel variant c.1444-8_1444-6delTCC in NM_001134775.1) showed low-frequrncy heaing impairment. In addition, in some hereditary hearing loss families, including TECTA (DFNB21) ${ }^{45-47}$, EYA4 (DFNA10) ${ }^{48-50}$, COL11A2 (DFNA13) ${ }^{51}$, and CCDC50 (DFNA44) ${ }^{52}$, hearing impairment begins in the middle frequencies. 
These studies indicate that there are differences in the expression and/or specific functions of certain genes in the HCs in the different turns of the cochlea. Here we present a novel gene that has a specific role in the low-frequency region. We wondered what would cause the apical OHCs to be more vulnerable in KIc2-null mice, and we first hypothesized that different expression levels of Klc2 in the basilar membrane is the main reason for this phenotype. However, we did not find any significant differences in mRNA levels between the different turns of the cochlea by q-PCR analysis, and we were unfortunately unable to obtain antibodies suitable for immunolabeling to study its expression pattern at the protein level. We then hypothesized that changes in the overall morphological structure of the cochlea account for this and that HCs might suffer from squeezing stress of cupula cochleae. We examined WT and KIc2null cochleae at P40 and found no obvious differences between them. Thus more factors need to be considered, like the microenvironment, different types of efferent nerve receptors, or other Klc2-related genes that have distinct expression patterns. These factors might play a role alone or together, and they might collectively determine the survival of HCs in the different turns of the cochlea.

Mitochondrial transport is mediated by kinesin and relies on an intact microtubule network. In neurons, the motor/adaptor complex consisting of two core proteins called Miro (also known as RhoT1 and RhoT2) and Milton (also known as TRAK1 and TRAK2) connect the mitochondria to kinesin (or dynein), which allows the mitochondria to be transported along the microtubules ${ }^{53-56}$. In our mouse model, mitochondrial distribution was changed in $\mathrm{HCs}$, and we therefore speculate that mitochondria might use a similar kinesin-mediated transport mode in HCs. Supplying ATPs from the respiratory chain, mitochondria are concentrated in areas with strong metabolism, and abnormal distribution of mitochondria may lead to cell dysfunction. Bavister found that the distribution of mitochondria changes in different groups of mammals during oocyte maturation or fertilization ${ }^{57}$, while Pathi showed that oxygen controls the intracellular distribution of mitochondria in muscle fibers, and a more asymmetric mitochondrial distribution presumably results in increased ROS production ${ }^{34}$. In the HCs of the cochlea, mitochondria are concentrated along the plasma membrane, under the cuticular plate, and around the nucleus $^{33}$ in order to provide energy for stereocilia movement, ion channels, and synaptic activity. In our model, deficiency of Klc2 caused abnormal mitochondrial distribution and ultimately led to HC death. This study proves that mitochondrial transport in cochlear HCs relies on Klc2, and it provides new evidence that mitochondria need to be transported to the proper intracellular position in order to maintain cell survival.

As one of the motor protein subunits, $\mathrm{Klc2}$ is widely expressed, but loss of Klc2 only results in hearing loss. To investigate the reason for $\mathrm{OHC}$ death, we checked the mitochondria's known functions and found that $\mathrm{OHC}$ death was not related to apoptosis, autophagy, or excessive ROS production, at least suggesting that the above function of mitochondria is not affected when its localization was changed. After ruling out the above mitochondrial function, we thought that two possible reasons might explain why only HC death is seen in KIc2-null mice. The first is that other Klcs (Klc1, Klc3, or Klc4) cannot compensate for Klc2's function in the cochlea, which we showed to be the case. The online database https://shield.hms.harvard.edu/ showed that Klc2 has the highest expression ratio in HCs compared to 
other types of cells in the cochlea, which implies that Klc2 plays a major role in HCs compared to other KLCs, and in other tissues the other KLCs might compensate for the functions of Klc2. Second, we thought that mitochondria transport might be more sensitive in HCs than in other types of cells. In addition to maintaining basic life activities, mitochondria also supply more energy for special activities like stereocilium motion for sound signal transmission, synapse activity for both information transfer and protective efferent suppression (like GABA as discussed below) ${ }^{8}$, all of which require timely energy production from the mitochondria. Insufficient energy supply will impede the normal functions of HCs, causing the loss of cellular communication or even influencing basic metabolism, eventually resulting in cell death. In addition, we performed the AAV rescue experiment to reexpress Klc2 only in the cochlea and observed recovery of function, indicating that loss of HCs is autonomous. Taken together, these results suggest that $\mathrm{Klc} 2$ is essential for $\mathrm{HC}$ function in the cochlea, but not in other tissues.

We further performed RNA-seq to investigate the mechanism behind the $\mathrm{HC}$ death seen in KIc2-null mice. Of the changes in gene expression, we focused on the GABAA receptor, which is an inhibitory neurotransmitter receptor that is associated with hearing protection through the olivocochlear efferent system. A total of 21 receptor subunits have been identified, but most GABAA receptors are pentamers composed of 5 subunits $-2 a, 2 \beta$, and $1 y$ subunit - and the different spatial expression patterns and distinct properties of these subunits allow the GABAA receptor to play different roles ${ }^{58}$. GABA receptor, which expression and function in cochlea were wildly reported, is thought to transmit inhibitory messages that protect HCs from over-excitation. Whitlon and Sobkowicz reported that GABA-positive fibers are expressed along the entire length of the basilar membrane but that innervation of OHCs is restricted to the apical and middle turns ${ }^{59}$, which conforms to the pattern of $\mathrm{OHC}$ death in our model. However, one study using different immunologic markers indicated the presence of GABAergic terminals on OHCs throughout the whole cochlea ${ }^{60}$. It is noteworthy that deletion of Gabrb3 (GABAA receptor subunit $\beta 3$ ) caused low-frequency hearing loss, similar to the phenotype of KIc2-null mice ${ }^{39}$. In our study, deficiency of Klc2 resulted in decreased expression of multiple GABAA receptor subunits, which might lead to the inhibition of cochlear efferent nerve protection and eventually lead to the death of OHCs. Moreover, it is generally acknowledged that mitochondria are essential for synapses. Mitochondria buffer cytoplasmic calcium and provide energy to ensure the function and plasticity of synapses ${ }^{61 ; 62}$. Strikingly, Verstreken reported that Drp1-knockout flies showed defects in mitochondrial localization, and lacking of energy supply then lead to synaptic depression ${ }^{63}$. And another interesting study recently showed mitochondria can sequester GABA to reduce GABA neurotransmission, even cause social behavioral impairments in Drosophila ${ }^{64}$. Taken together, we presumed that, in our model, reduced expression of GABAA receptor subunits may on account of some abnormal mitochondria activities or functions. However, we cannot exclude the possibility that whether changes in GABAA receptor were directly effect of $K I c 2$ deletion, thus, the relationship between GABAA receptor and mitochondria in HCs remain to be studied next.

In summary, we present the role of the novel deafness-related gene $K I c 2$, which caused unusual lowfrequency hearing defects both in mice and human, and we discuss the reasons for hearing loss in KIc2null mice. We provide new evidence that abnormal mitochondrial distribution can affect normal cellular 
activities, and our work lays the foundation for research on the role of motor proteins in the auditory system.

\section{Declarations}

\section{Funding}

This work was supported by grants from the National Key R\&D Program of China (2019YFA0111400), Strategic Priority Research Program of the Chinese Academy of Science (XDA16010303), National Key R\&D Program of China区Nos. SQ2020YFA010013, 2017YFA0103903区, the National Science Foundation of China (Nos. 81900937, 82030029, 81970882), Natural Science Foundation from Jiangsu Province (BE2019711), Shenzhen Fundamental Research Program (JCYJ20190814093401920), Boehringer Ingelheim Pharma GmbH, and Open Research Fund of State Key Laboratory of Genetic Engineering, Fudan University(No. SKLGE1809).

Author Contributions

Renjie Chai and Jiangang Gao designed and supervised the project. Xiaolong Fu, Yachun An, Peipei Li, Jing Lin, Jia Yuan, Rongyu Yue and Yecheng Jin performed most experiments and acquired the data. Hongyang Wang screened and analyzed clinical data. Xiaolong Fu, Yachun An, Peipei Li, Jing Lin, Jia Yuan, Rongyu Yue and Yecheng Jin analyzed and interpreted the experiments results. Xiaolong Fu, Yachun An and Renjie Chai wrote the manuscript.

Availability of data and material

The datasets used or analyzed during the current study are available from the corresponding author on reasonable request.

Declaration of Interests

The authors declare no conflict of interests.

Ethical approval

We performed all animal procedures according to protocols that were approved by the Animal Care and Use Committee of Southeast University and that were consistent with the National Institute of Health's Guide for the Care and Use of Laboratory Animals. We made all efforts to minimize the number of animals used and to prevent their suffering.

Consent to participate

Informed consent to participate in the study was obtained from all participants

Consent for Publication 
All authors consent to the publication of current data.

\section{References}

1. Hammer MS, Swinburn TK, Neitzel RL (2014) Environmental noise pollution in the United States: developing an effective public health response. Environmental health perspectives 122:115-119

2. Forge A, Schacht J (2000) Aminoglycoside antibiotics. Audiol Neuro-otol 5:3-22

3. Garinis AC, Cross CP, Srikanth P, Carroll K, Feeney MP, Keefe DH, Hunter LL, Putterman DB, Cohen DM, Gold JA et al (2017) The cumulative effects of intravenous antibiotic treatments on hearing in patients with cystic fibrosis. Journal of cystic fibrosis: official journal of the European Cystic Fibrosis Society 16:401-409

4. Duggal P, Sarkar M (2007) Audiologic monitoring of multi-drug resistant tuberculosis patients on aminoglycoside treatment with long term follow-up. BMC ear, nose, and throat disorders 7, 5

5. Allen PD, Eddins DA (2010) Presbycusis phenotypes form a heterogeneous continuum when ordered by degree and configuration of hearing loss. Hearing research 264:10-20

6. Christensen K, Frederiksen H, Hoffman HJ (2001) Genetic and environmental influences on selfreported reduced hearing in the old and oldest old. J Am Geriatr Soc 49:1512-1517

7. Richardson GP, de Monvel JB, Petit C (2011) How the genetics of deafness illuminates auditory physiology. Annu Rev Physiol 73:311-334

8. Fettiplace R (2017) Hair Cell Transduction, Tuning, and Synaptic Transmission in the Mammalian Cochlea. Comprehensive Physiology 7:1197-1227

9. Belyantseva IA, Boger ET, Naz S, Frolenkov GI, Sellers JR, Ahmed ZM, Griffith AJ, Friedman TB (2005) Myosin-XVa is required for tip localization of whirlin and differential elongation of hair-cell stereocilia. Nat Cell Biol 7:148-156

10. Delprat B, Michel V, Goodyear R, Yamasaki Y, Michalski N, El-Amraoui A, Perfettini I, Legrain P, Richardson G, Hardelin JP et al (2005) Myosin XVa and whirlin, two deafness gene products required for hair bundle growth, are located at the stereocilia tips and interact directly. Human molecular genetics 14:401-410

11. Kikkawa Y, Mburu P, Morse S, Kominami R, Townsend S, Brown SD (2005) Mutant analysis reveals whirlin as a dynamic organizer in the growing hair cell stereocilium. Human molecular genetics 14:391-400

12. Schneider ME, Dosé AC, Salles FT, Chang W, Erickson FL, Burnside B, Kachar B (2006) A new compartment at stereocilia tips defined by spatial and temporal patterns of myosin Illa expression. The Journal of neuroscience: the official journal of the Society for Neuroscience 26:10243-10252

13. Rzadzinska AK, Nevalainen EM, Prosser HM, Lappalainen P, Steel KP (2009) MyosinVlla interacts with Twinfilin-2 at the tips of mechanosensory stereocilia in the inner ear. PloS one 4:e7097

14. Paavilainen VO, Hellman M, Helfer E, Bovellan M, Annila A, Carlier MF, Permi P, Lappalainen P (2007) Structural basis and evolutionary origin of actin filament capping by twinfilin. Proc Natl Acad Sci 
USA 104:3113-3118

15. Peng AW, Belyantseva IA, Hsu PD, Friedman TB, Heller S (2009) Twinfilin 2 regulates actin filament lengths in cochlear stereocilia. The Journal of neuroscience: the official journal of the Society for Neuroscience 29:15083-15088

16. Palmgren S, Ojala PJ, Wear MA, Cooper JA, Lappalainen P (2001) Interactions with PIP2, ADP-actin monomers, and capping protein regulate the activity and localization of yeast twinfilin. J Cell Biol 155:251-260

17. Vale RD (2003) The molecular motor toolbox for intracellular transport. Cell 112:467-480

18. Inomata H, Nakamura Y, Hayakawa A, Takata H, Suzuki T, Miyazawa K, Kitamura N (2003) A scaffold protein JIP-1b enhances amyloid precursor protein phosphorylation by JNK and its association with kinesin light chain 1. J Biol Chem 278:22946-22955

19. Rath O, Kozielski F (2012) Kinesins and cancer. Nature reviews Cancer 12:527-539

20. Varadi A, Ainscow EK, Allan VJ, Rutter GA (2002) Involvement of conventional kinesin in glucosestimulated secretory granule movements and exocytosis in clonal pancreatic beta-cells. Journal of cell science 115:4177-4189

21. Rahman A, Friedman DS, Goldstein LS (1998) Two kinesin light chain genes in mice. Identification and characterization of the encoded proteins. J Biol Chem 273:15395-15403

22. Batut J, Howell M, Hill CS (2007) Kinesin-mediated transport of Smad2 is required for signaling in response to TGF-beta ligands. Developmental cell 12:261-274

23. McGuire JR, Rong J, Li SH, Li XJ (2006) Interaction of Huntingtin-associated protein-1 with kinesin light chain: implications in intracellular trafficking in neurons. J Biol Chem 281:3552-3559

24. Du J, Wei Y, Liu L, Wang Y, Khairova R, Blumenthal R, Tragon T, Hunsberger JG, Machado-Vieira R, Drevets W et al (2010) A kinesin signaling complex mediates the ability of GSK-3beta to affect moodassociated behaviors. Proc Natl Acad Sci USA 107:11573-11578

25. Fu X, Sun X, Zhang L, Jin Y, Chai R, Yang L, Zhang A, Liu X, Bai X, Li J et al (2018) Tuberous sclerosis complex-mediated mTORC1 overactivation promotes age-related hearing loss. J Clin Investig 128:4938-4955

26. Winding M, Kelliher MT, Lu W, Wildonger J, Gelfand VI (2016) Role of kinesin-1-based microtubule sliding in Drosophila nervous system development. Proc Natl Acad Sci USA 113:E4985-E4994

27. Sato T, Ishikawa M, Mochizuki M, Ohta M, Ohkura M, Nakai J, Takamatsu N, Yoshioka K (2015) JSAP1/JIP3 and JLP regulate kinesin-1-dependent axonal transport to prevent neuronal degeneration. Cell death differentiation 22:1260-1274

28. Doll S, Freitas FP, Shah R, Aldrovandi M, da Silva MC, Ingold I, Grocin G, da Silva AXavier, Panzilius TN, Scheel E, C.H., et al (2019) FSP1 is a glutathione-independent ferroptosis suppressor. Nature 575:693-698

29. Slepecky N, Chamberlain SC (1985) Immunoelectron microscopic and immunofluorescent localization of cytoskeletal and muscle-like contractile proteins in inner ear sensory hair cells. 
Hearing research 20:245-260

30. Hasson T, Gillespie PG, Garcia JA, MacDonald RB, Zhao Y, Yee AG, Mooseker MS, Corey DP (1997) Unconventional myosins in inner-ear sensory epithelia. J Cell Biol 137:1287-1307

31. Liu Y, Qi J, Chen X, Tang M, Chu C, Zhu W, Li H, Tian C, Yang G, Zhong C et al (2019) Critical role of spectrin in hearing development and deafness. Sci Adv 5:eaav7803

32. Fu X, Zhang L, Jin Y, Sun X, Zhang A, Wen Z, Zhou Y, Xia M, Gao J (2016) Loss of Myh14 Increases Susceptibility to Noise-Induced Hearing Loss in CBAVCaJ Mice. Neural plasticity 2016, 6720420

33. Ikeda K, Takasaka T (1993) Confocal laser microscopical images of calcium distribution and intracellular organelles in the outer hair cell isolated from the guinea pig cochlea. Hearing research 66:169-176

34. Pathi B, Kinsey ST, Locke BR (2013) Oxygen control of intracellular distribution of mitochondria in muscle fibers. Biotechnol Bioeng 110:2513-2524

35. Singh H, Lu R, Bopassa JC, Meredith AL, Stefani E, Toro L (2013) MitoBK(Ca) is encoded by the Kcnma1 gene, and a splicing sequence defines its mitochondrial location. Proc Natl Acad Sci USA 110:10836-10841

36. Kathiresan T, Harvey M, Orchard S, Sakai Y, Sokolowski B (2009) A protein interaction network for the large conductance $\mathrm{Ca}(2+)$-activated $\mathrm{K}(+)$ channel in the mouse cochlea. MCP 8 , Molecular \& cellular proteomics, pp 1972-1987

37. Sakai Y, Harvey M, Sokolowski B (2011) Identification and quantification of full-length BK channel variants in the developing mouse cochlea. J Neurosci Res 89:1747-1760

38. Doleviczényi Z, Halmos G, Répássy G, Vizi ES, Zelles T, Lendvai B (2005) Cochlear dopamine release is modulated by group II metabotropic glutamate receptors via GABAergic neurotransmission. Neurosci Lett 385:93-98

39. Maison SF, Rosahl TW, Homanics GE, Liberman MC (2006) Functional role of GABAergic innervation of the cochlea: phenotypic analysis of mice lacking GABA(A) receptor subunits alpha 1, alpha 2, alpha 5, alpha 6, beta 2, beta 3, or delta. The Journal of neuroscience: the official journal of the Society for Neuroscience 26:10315-10326

40. Batta TJ, Panyi G, Szucs A, Sziklai I (2004) Regulation of the lateral wall stiffness by acetylcholine and GABA in the outer hair cells of the guinea pig. Eur $J$ Neurosci 20:3364-3370

41. Landegger LD, Pan B, Askew C, Wassmer SJ, Gluck SD, Galvin A, Taylor R, Forge A, Stankovic KM, Holt JR et al (2017) A synthetic AAV vector enables safe and efficient gene transfer to the mammalian inner ear. Nature biotechnology 35:280-284

42. Cryns K, Sivakumaran TA, Van den Ouweland JM, Pennings RJ, Cremers CW, Flothmann K, Young TL, Smith RJ, Lesperance MM, Van Camp G (2003) Mutational spectrum of the WFS1 gene in Wolfram syndrome, nonsyndromic hearing impairment, diabetes mellitus, and psychiatric disease. Hum Mutat 22:275-287

43. Lynch ED, Lee MK, Morrow JE, Welcsh PL, León PE, King MC (1997) Nonsyndromic deafness DFNA1 associated with mutation of a human homolog of the Drosophila gene diaphanous. Science 


\section{8:1315-1318}

44. León PE, Bonilla JA, Sánchez JR, Vanegas R, Villalobos M, Torres L, León F, Howell AL, Rodríguez JA (1981) Low frequency hereditary deafness in man with childhood onset. Am J Hum Genet 33:209214

45. Mustapha M, Weil D, Chardenoux S, Elias S, El-Zir E, Beckmann JS, Loiselet J, Petit C (1999) An alpha-tectorin gene defect causes a newly identified autosomal recessive form of sensorineural prelingual non-syndromic deafness, DFNB21. Human molecular genetics 8:409-412

46. Meyer NC, Alasti F, Nishimura CJ, Imanirad P, Kahrizi K, Riazalhosseini Y, Malekpour M, Kochakian N, Jamali $P$, Van Camp $G$ et al (2007) Identification of three novel TECTA mutations in Iranian families with autosomal recessive nonsyndromic hearing impairment at the DFNB21 locus. American journal of medical genetics Part A 143a:1623-1629

47. Naz S, Alasti F, Mowjoodi A, Riazuddin S, Sanati MH, Friedman TB, Griffith AJ, Wilcox ER, Riazuddin S (2003) Distinctive audiometric profile associated with DFNB21 alleles of TECTA. J Med Genet 40:360-363

48. Hildebrand MS, Coman D, Yang T, Gardner RJ, Rose E, Smith RJ, Bahlo M, Dahl HH (2007) A novel splice site mutation in EYA4 causes DFNA10 hearing loss. American journal of medical genetics Part A 143a:1599-1604

49. Wayne S, Robertson NG, DeClau F, Chen N, Verhoeven K, Prasad S, Tranebjärg L, Morton CC, Ryan AF, Van Camp G et al (2001) Mutations in the transcriptional activator EYA4 cause late-onset deafness at the DFNA10 locus. Human molecular genetics 10:195-200

50. Makishima T, Madeo AC, Brewer CC, Zalewski CK, Butman JA, Sachdev V, Arai AE, Holbrook BM, Rosing DR, Griffith AJ (2007) Nonsyndromic hearing loss DFNA10 and a novel mutation of EYA4: evidence for correlation of normal cardiac phenotype with truncating mutations of the Eya domain. American journal of medical genetics Part A 143a:1592-1598

51. McGuirt WT, Prasad SD, Griffith AJ, Kunst HP, Green GE, Shpargel KB, Runge C, Huybrechts C, Mueller RF, Lynch E et al (1999) Mutations in COL11A2 cause non-syndromic hearing loss (DFNA13). Nat Genet 23:413-419

52. Modamio-Hoybjor S, Mencia A, Goodyear R, del Castillo I, Richardson G, Moreno F, Moreno-Pelayo MA (2007) A mutation in CCDC50, a gene encoding an effector of epidermal growth factor-mediated cell signaling, causes progressive hearing loss. Am J Hum Genet 80:1076-1089

53. Stowers RS, Megeath LJ, Górska-Andrzejak J, Meinertzhagen IA, Schwarz TL (2002) Axonal transport of mitochondria to synapses depends on milton, a novel Drosophila protein. Neuron 36:1063-1077

54. Fransson A, Ruusala A, Aspenström P (2003) Atypical Rho GTPases have roles in mitochondrial homeostasis and apoptosis. J Biol Chem 278:6495-6502

55. Fransson S, Ruusala A, Aspenström P (2006) The atypical Rho GTPases Miro-1 and Miro-2 have essential roles in mitochondrial trafficking. Biochem Biophys Res Commun 344:500-510

56. Brickley K, Stephenson FA (2011) Trafficking kinesin protein (TRAK)-mediated transport of mitochondria in axons of hippocampal neurons. J Biol Chem 286:18079-18092 
57. Bavister BD, Squirrell JM (2000) Mitochondrial distribution and function in oocytes and early embryos. Human reproduction (Oxford England) 15(Suppl 2):189-198

58. Chebib M, Johnston GA (2000) GABA-Activated ligand gated ion channels: medicinal chemistry and molecular biology. Journal of medicinal chemistry 43:1427-1447

59. Whitlon DS, Sobkowicz HM (1989) GABA-like immunoreactivity in the cochlea of the developing mouse. J Neurocytol 18:505-518

60. Maison SF, Adams JC, Liberman MC (2003) Olivocochlear innervation in the mouse: immunocytochemical maps, crossed versus uncrossed contributions, and transmitter colocalization. J Comp Neurol 455:406-416

61. Todorova V, Blokland A (2017) Mitochondria and Synaptic Plasticity in the Mature and Aging Nervous System. Current neuropharmacology 15:166-173

62. Ly CV, Verstreken P (2006) Mitochondria at the synapse. The Neuroscientist: a review journal bringing neurobiology neurology psychiatry 12:291-299

63. Verstreken P, Ly CV, Venken KJ, Koh TW, Zhou Y, Bellen HJ (2005) Synaptic mitochondria are critical for mobilization of reserve pool vesicles at Drosophila neuromuscular junctions. Neuron 47:365-378

64. Kanellopoulos AK, Mariano V, Spinazzi M, Woo YJ, McLean C, Pech U, Li KW, Armstrong JD, Giangrande A, Callaerts $P$ et al (2020) Aralar Sequesters GABA into Hyperactive Mitochondria. Causing Social Behavior Deficits Cell 180:1178-1197.e1120

\section{Figures}



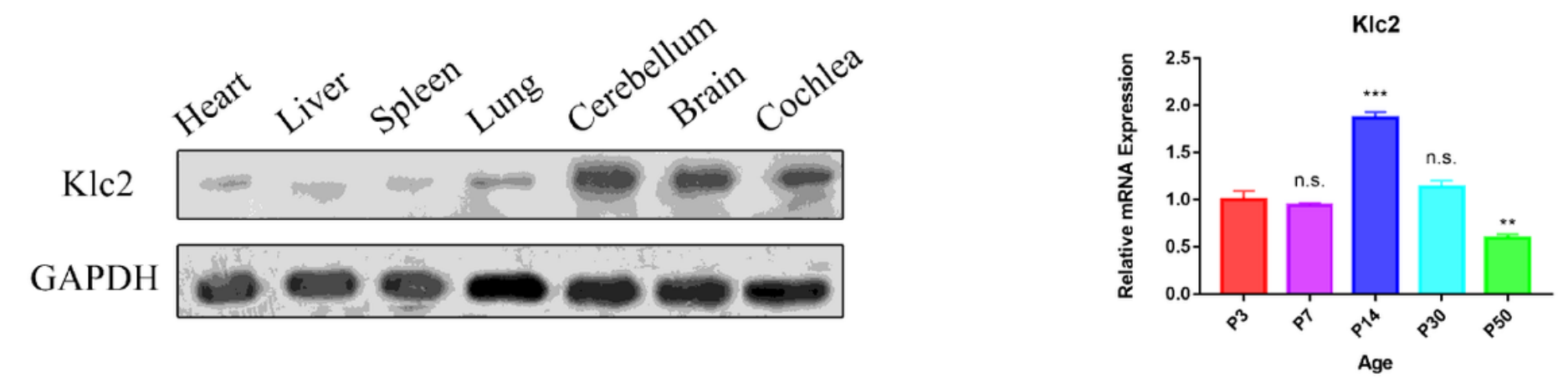

$\mathrm{C}$

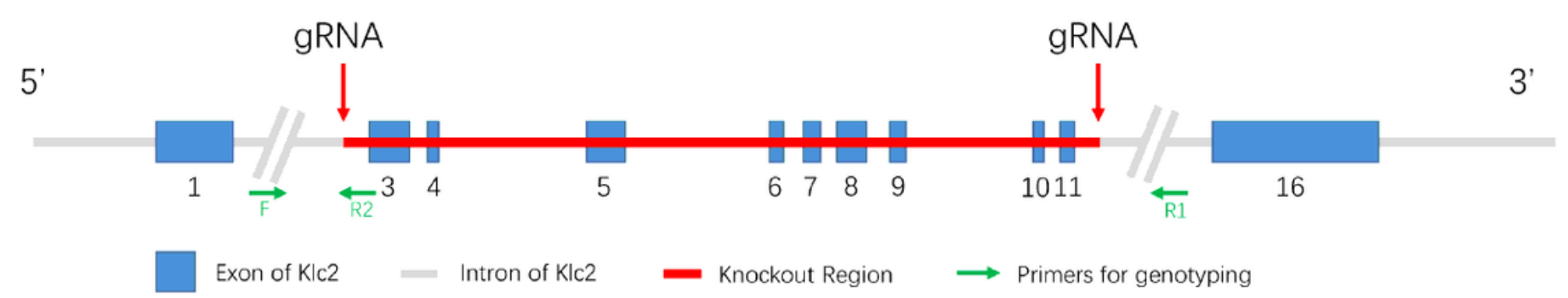

$\mathrm{D}$

$\mathrm{E}$

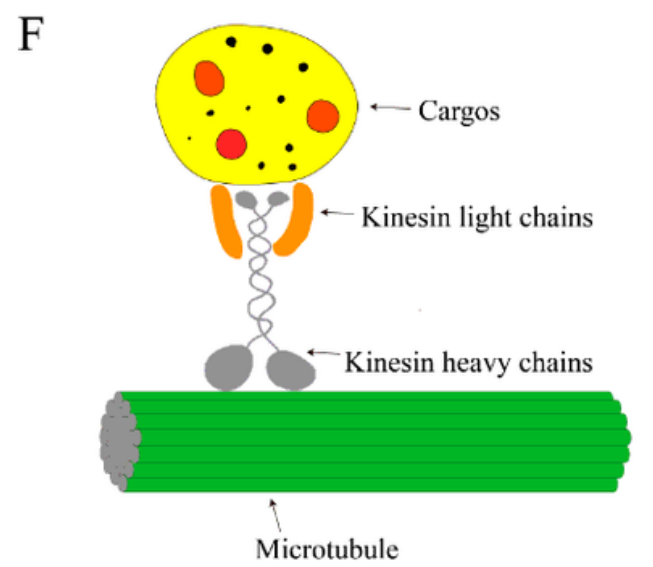

Figure 1

Klc2 knockout by CRISPR/Cas9 in C57BL/6J mice (A) Western blot analysis of Klc2 expression in WT mice. The expression of Klc2 in the cochlea was greater than that in the heart, liver, spleen, and lung but was less than that in the cerebellum and brain. (B) Q-PCR analysis showed that the expression of KIc2 was highest at P14 ( $p<0.001$ for P14, $p<0.01$ for P50. (C) Schematic of the Klc2 knockout strategy. Two individual sgRNAs were specific to intron 2 and intron 11, and the whole coding sequence was abolished. ( $D$ and E) Q-PCR and western blot analysis of the cochlea verified the knockout of Klc2 in mutant mice ( $p$ $<0.001$ ). (F) Schematic diagram of kinesin-1, consisting of two heavy chains and two light chains, that transport intracellular cargos along microtubules. 
A

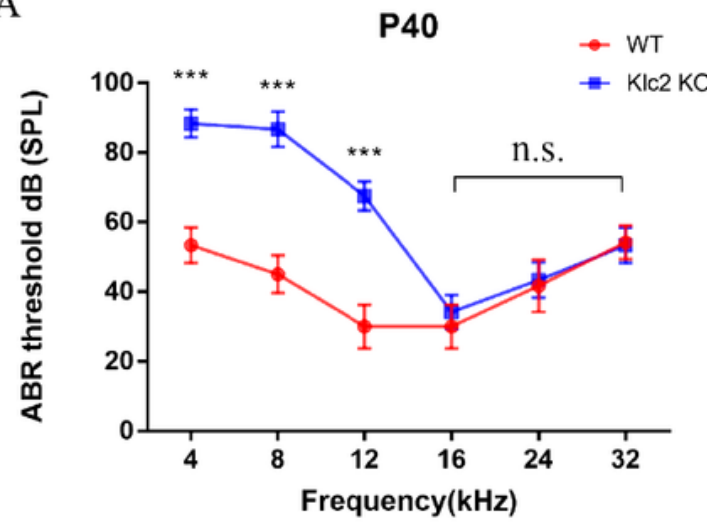

$\mathrm{C}$

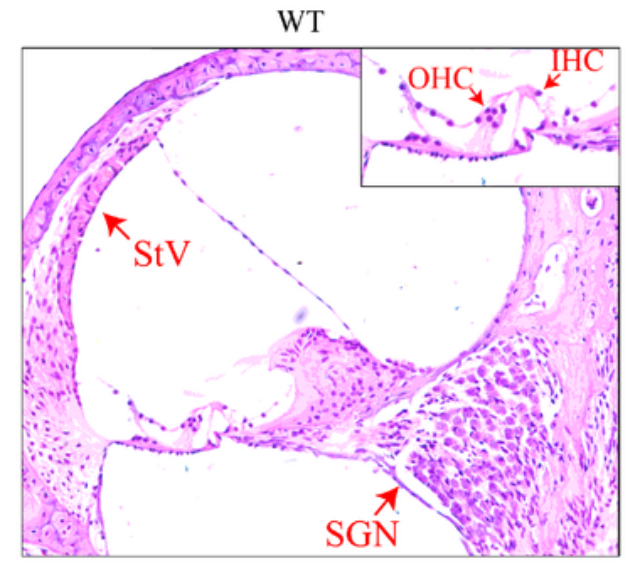

B
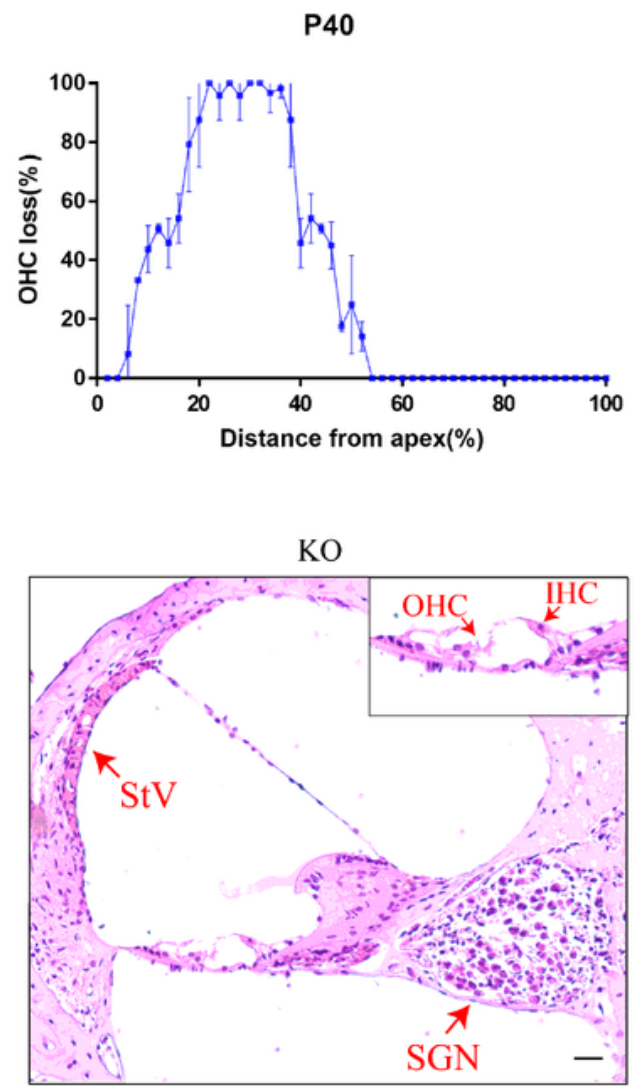

D
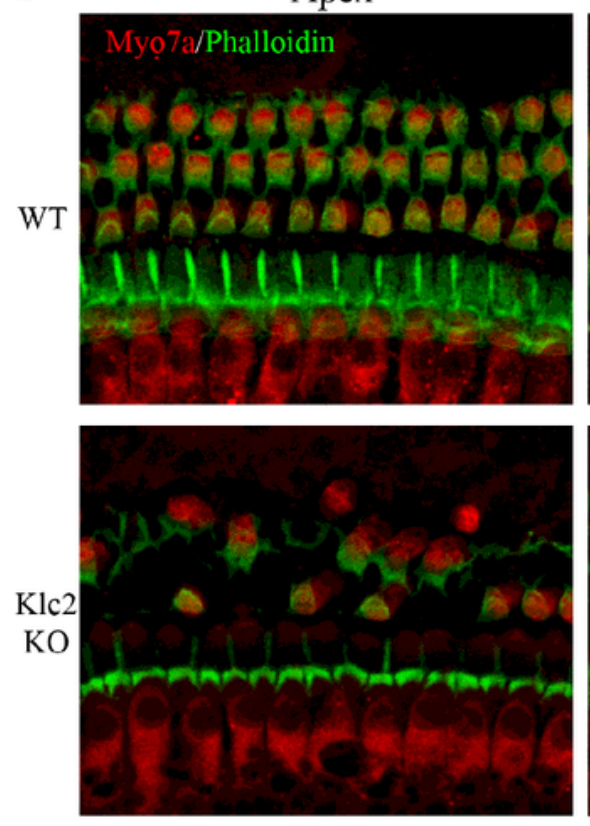

Middle
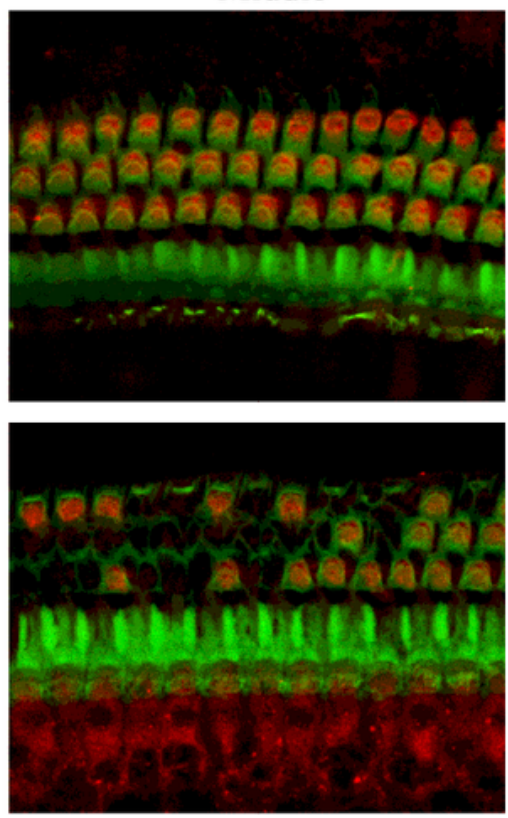

Base
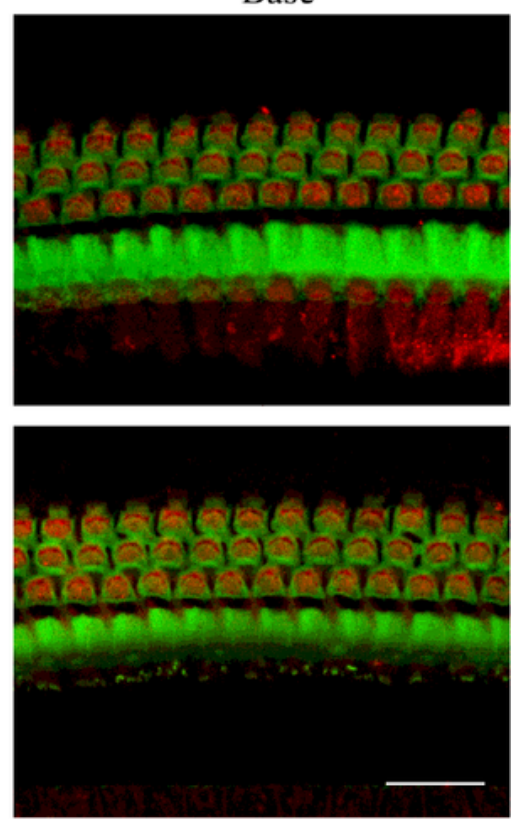

Figure 2

Klc2-null mice had low-frequency hearing loss and OHC degeneration (A) The ABR thresholds of Klc2-null mice were increased at $4 \mathrm{kHz}, 8 \mathrm{kHz}$, and $12 \mathrm{kHz}$ at P40 compared to WT littermates, $\mathrm{n}=6$. Data represent the mean $\pm S D$, $\star * \star ~ p<0.001$. (B) The missing OHCs were mainly in the apical turn of the basilar membrane. (C) WT and KIc2-null apical turn sections by H\&E staining at P40. OHCs were lost, but the IHCs, SGN, and StV were normal. Scale bar: $20 \mu \mathrm{m}$. (D) Representative confocal images of the basilar 
membrane stained with Myo7a (red) and phalloidin (green), which confirmed the loss of OHCs, $n=4$, Scale bar: $20 \mu \mathrm{m}$.

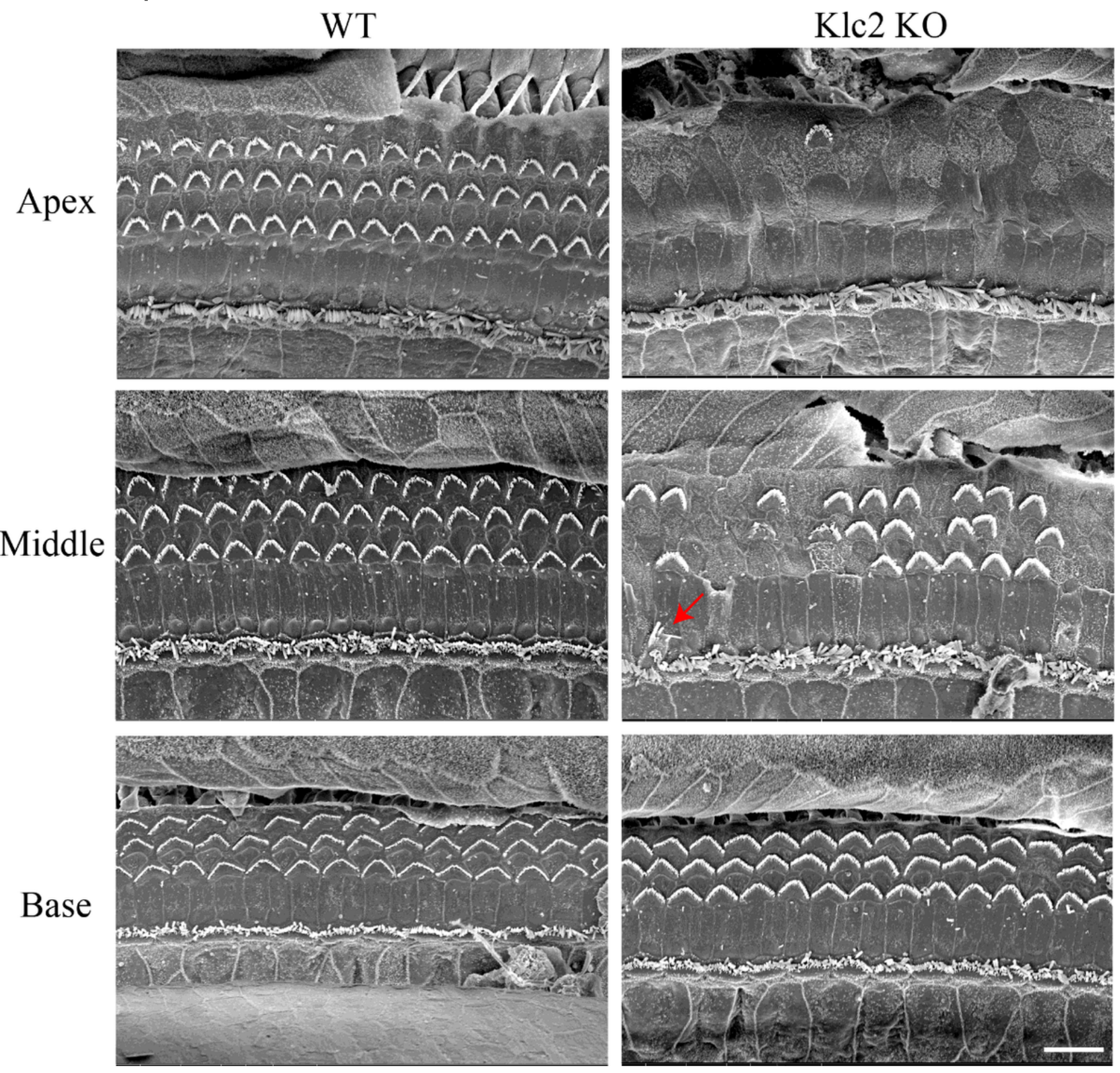

Figure 3

Representative SEM images of cochlear stereocilia bundles in different turns of Klc2-null and WT mice at P40. The arrow indicates the appearance of displaced IHCs, $n=3$, Scale bar: $10 \mu \mathrm{m}$ 

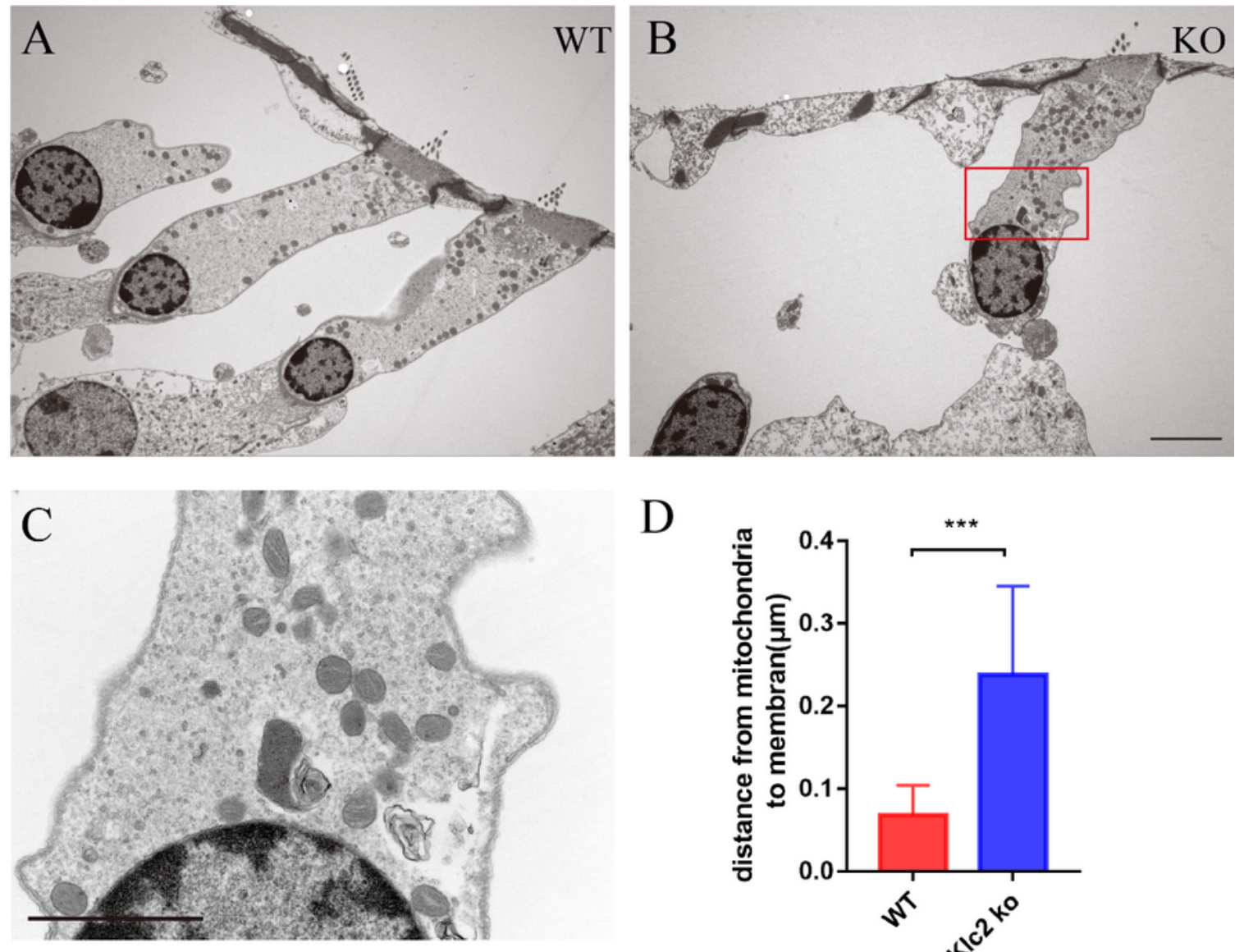

D

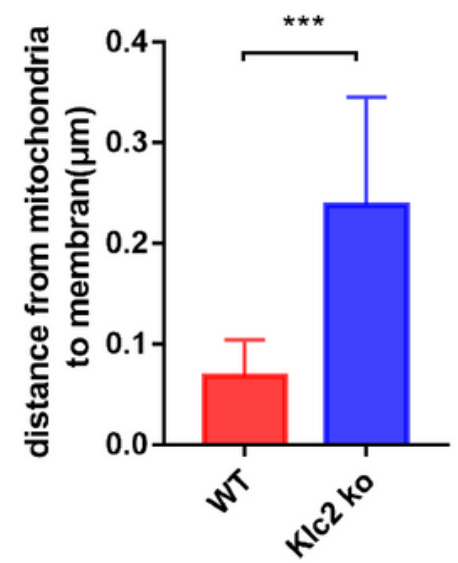

$\mathrm{E}$

$\mathrm{F}$
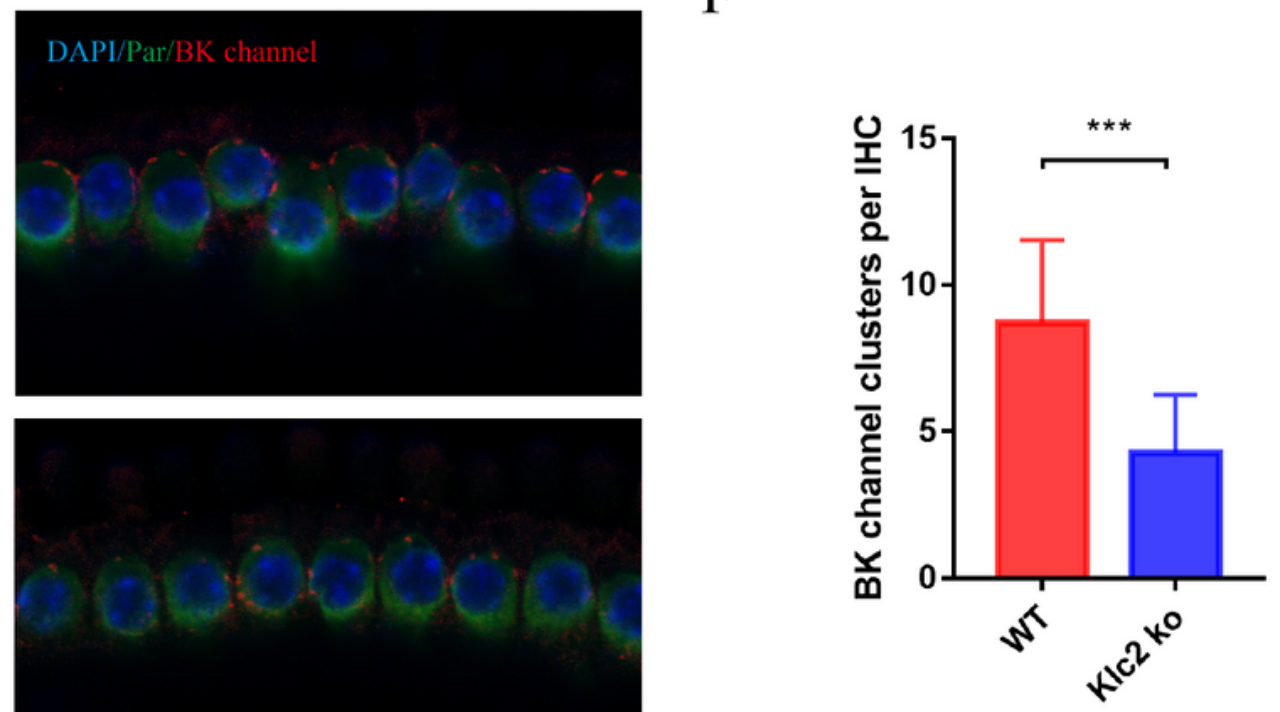

Figure 4

Deficiency of Klc2 disrupted mitochondrial localization in OHCs (A and B) TEM images of OHCs from WT and Klc2-null mice at P30 showed the abnormal distribution of mitochondria in mutant mice, $n=3$. Scale bar: $1 \mu \mathrm{m}$. (C) Enlarged image from the red box in Figure 4B. Scale bar: $0.5 \mu \mathrm{m}$. (D) Statistical histogram of the vertical distance from the mitochondria to the plasma membrane, $n=22$ for WT mice and $n=37$ for Klc2-null mice, ${ }^{* *} p<0.001$. ( $E$ and $F$ ) Representative confocal images and statistical histogram 
showing that the number of BK channel clusters decreased significantly in the mutant mice, $n=3$, ** $p<$ 0.001 , Scale bar: $20 \mu \mathrm{m}$.

A

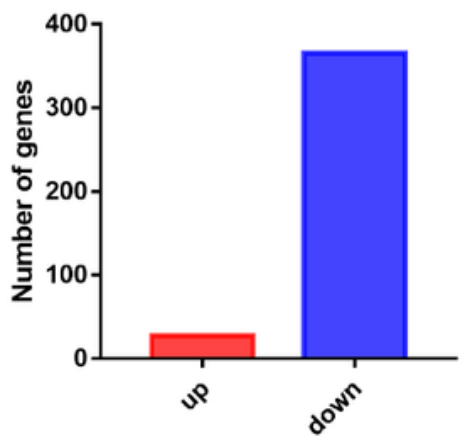

$\mathrm{C}$

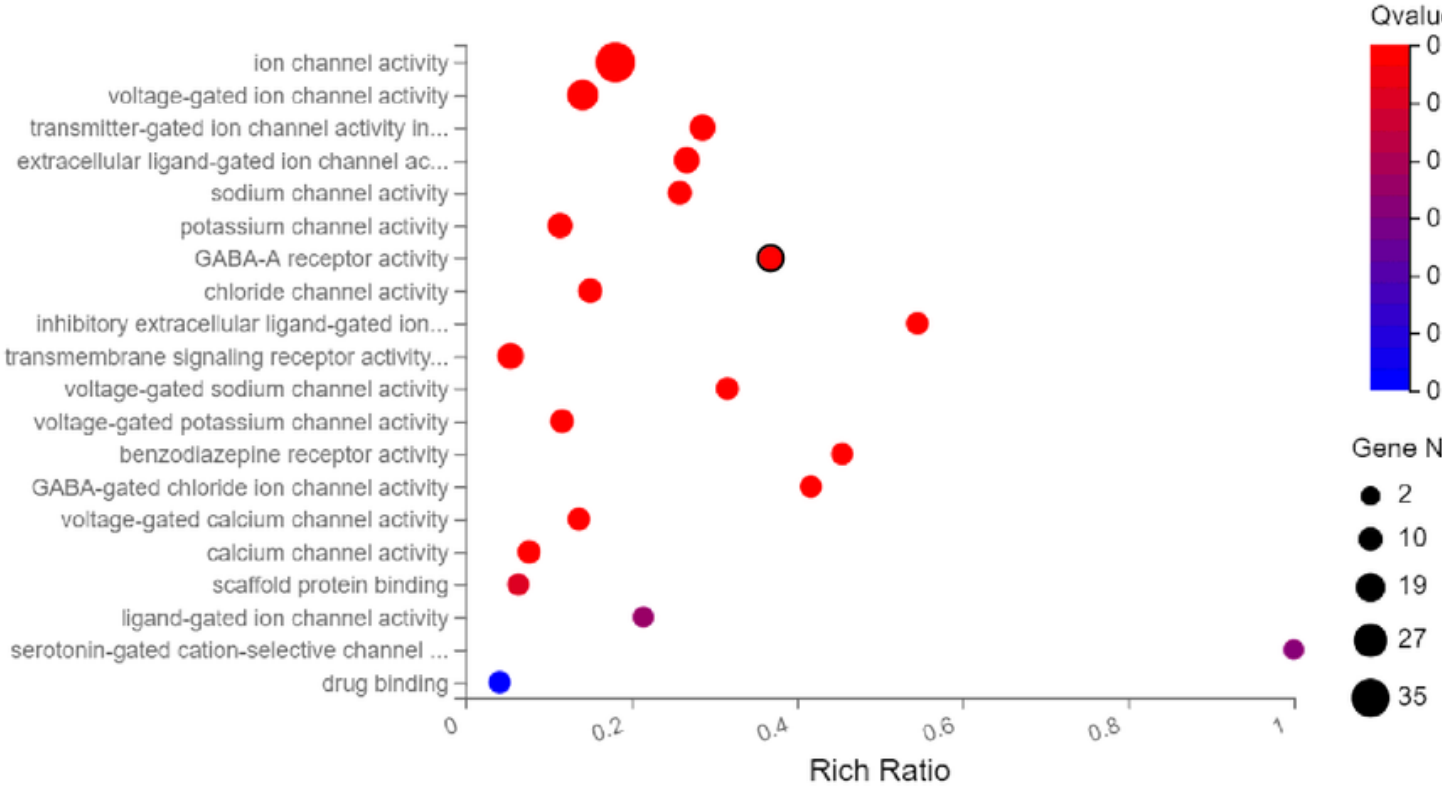

$\mathrm{D}$

\begin{tabular}{|c|c|}
\hline Gene & Fold change \\
\hline Gabra1 & 9.34 \\
\hline Gabrb2 & 3.02 \\
\hline Gabra3 & 2.29 \\
\hline Gabrd & 6.74 \\
\hline Gabra2 & 4.46 \\
\hline Gabra6 & 10.86 \\
\hline Gabrg1 & 4.13 \\
\hline
\end{tabular}

$\mathrm{E}$

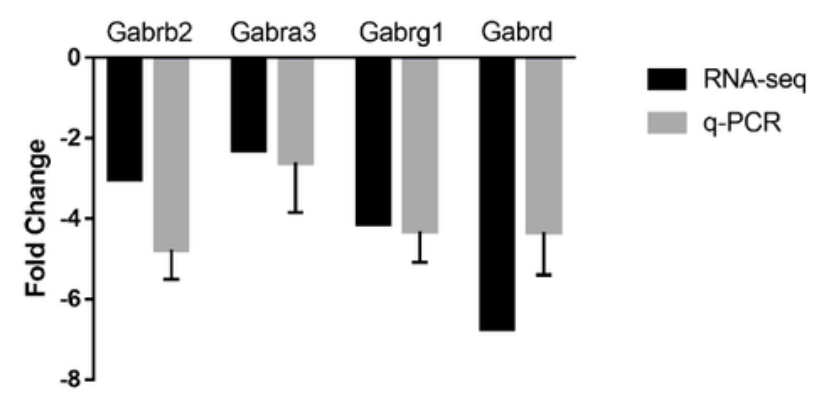

$\mathrm{B}$
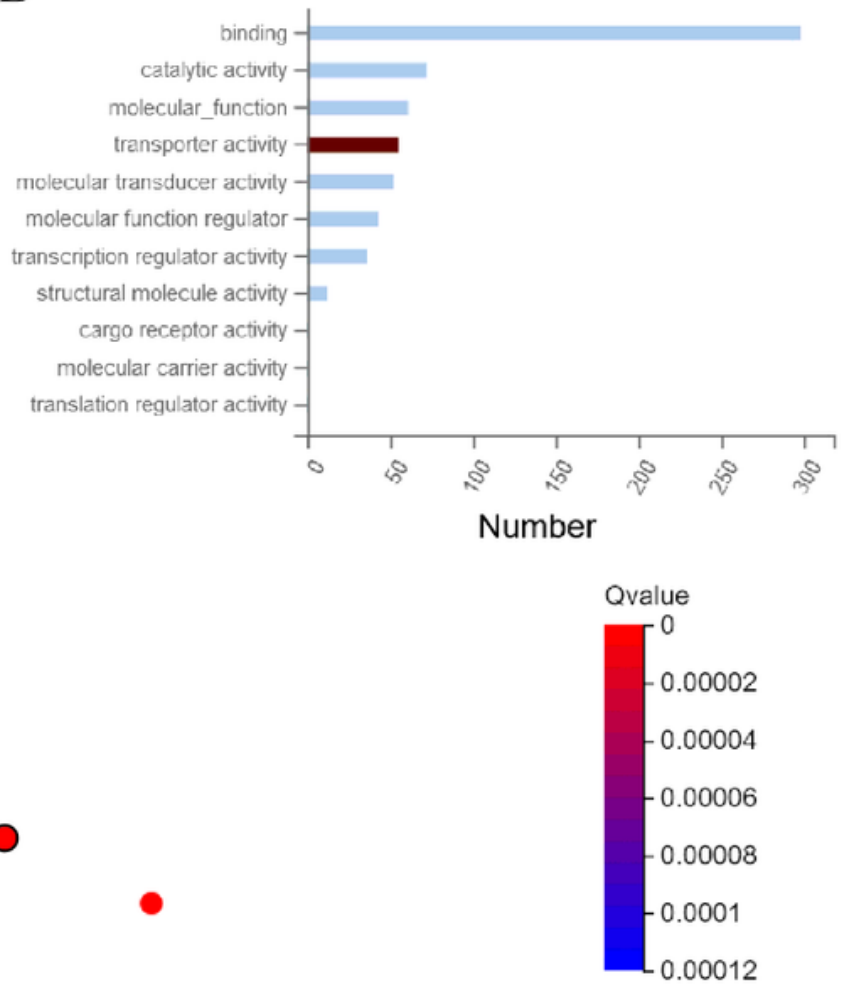

Gene Number

- 2

10

19

35

Figure 5

RNA-seq showed the down-regulation of the GABAA receptor family in Klc2-null mice (A) Histogram showing that 28 genes were up-regulated and 366 genes were down-regulated. (B) GO annotations of differentially expressed genes were classified and mapped, and "Transporter activity" (containing 55 
genes) is marked separately. (C) GO mf enrichment analysis of 55 genes, with "GABAA receptor activity" marked by a black circle. $Q<0.05$. (D) Gene symbols and fold changes of seven genes included in "GABAA receptor activity". (E) Q-PCR in KIc2-null mice to confirm the RNA-seq results. Negative numbers represent down-regulated expression, $\mathrm{n}=3$.

A

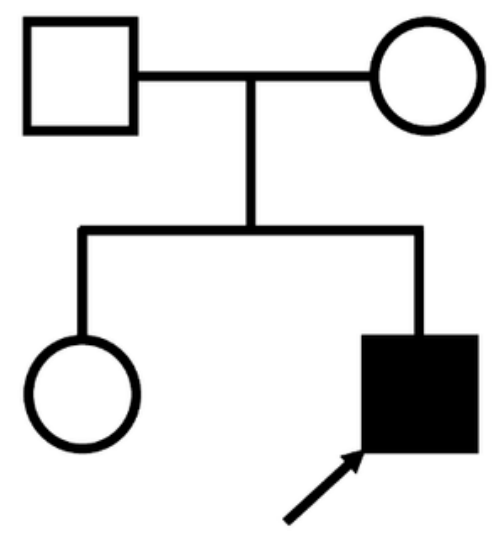

$\mathrm{C}$

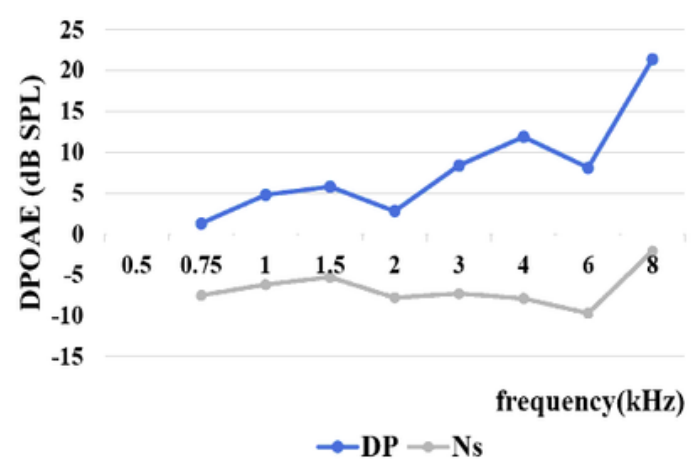

$\mathrm{B}$

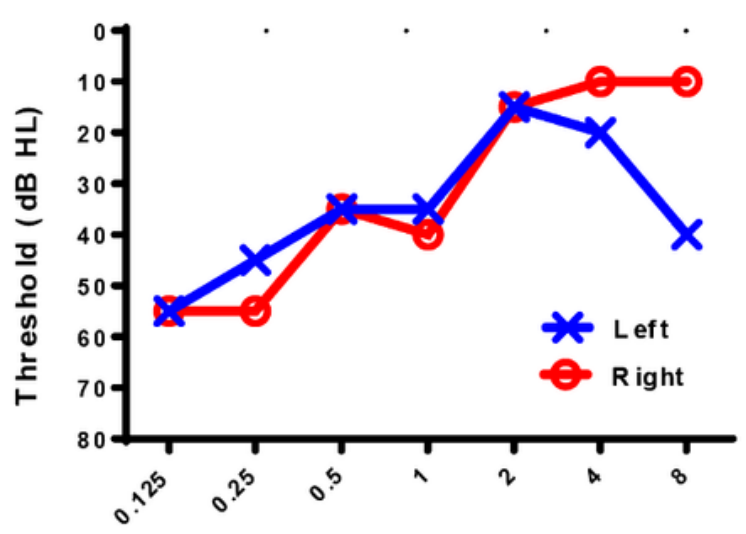

F requen cy ( $k H z)$

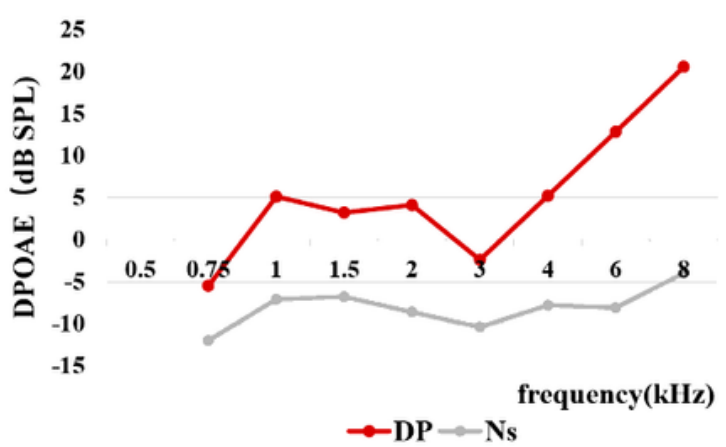

$\mathrm{D}$
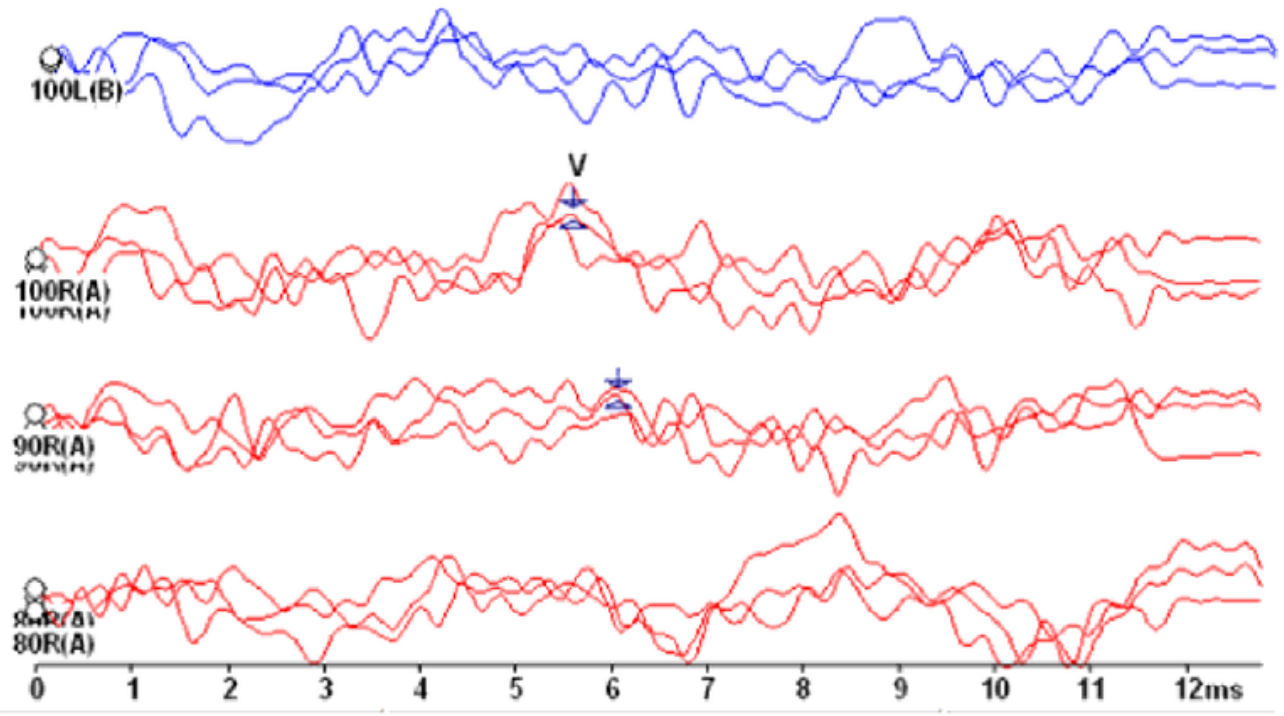

Figure 6 
Pedigree and audiological phenotype of case 1707652. (A) Pedigree of case 1707652. The affected subject is coloured black, the proband is indicated by an arrow. (B) Audiogram of the proband. (C) Normal DPOAE result of the proband. (D) ABR waves were absent in the left ear, and differentiated poorly in the right ear of the proband.

A

Cytoplasmic level
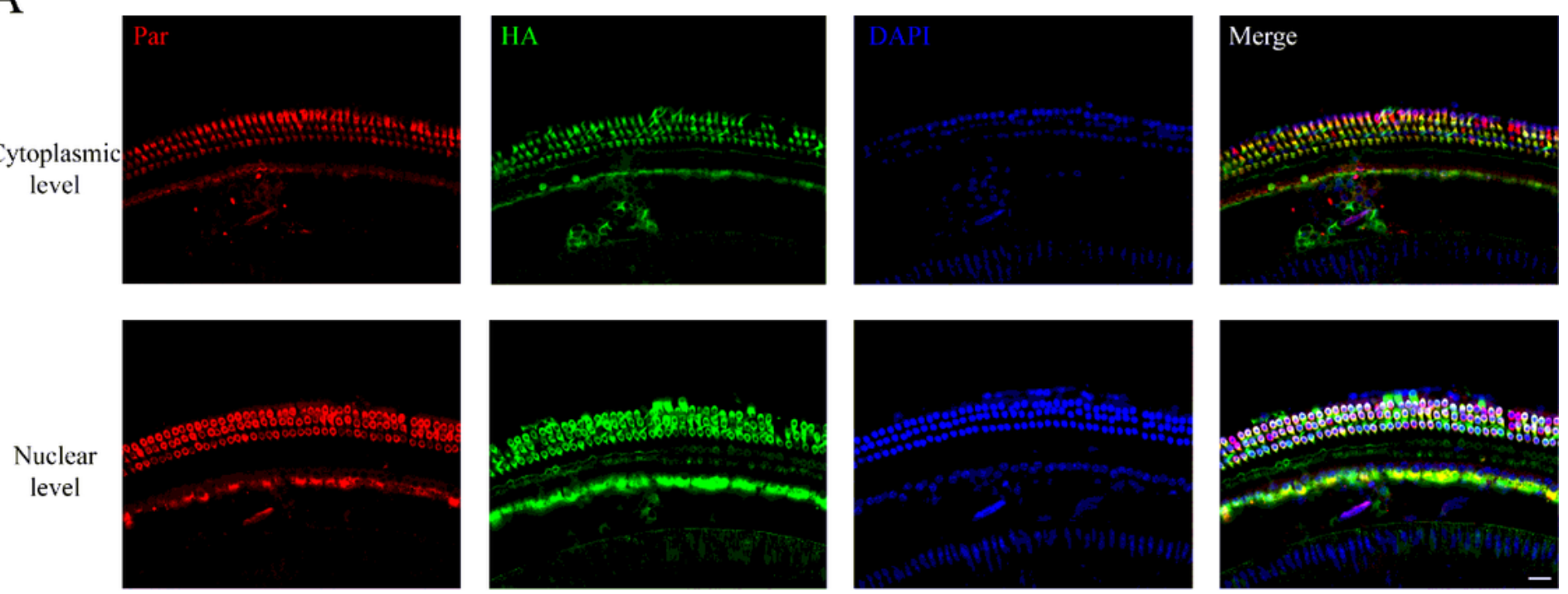

$\mathrm{B}$
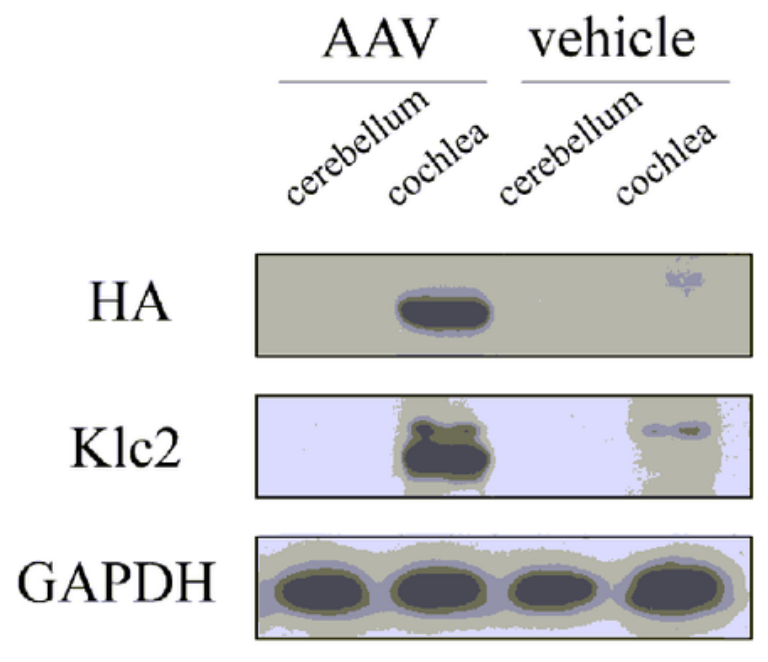

$\mathrm{C}$

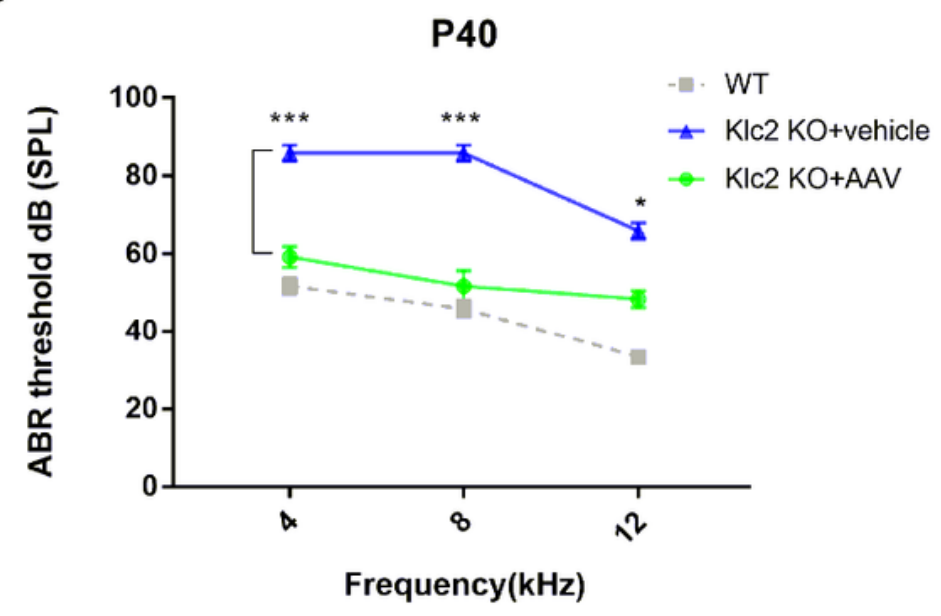

$\mathrm{D}$

Vehicle

AAV
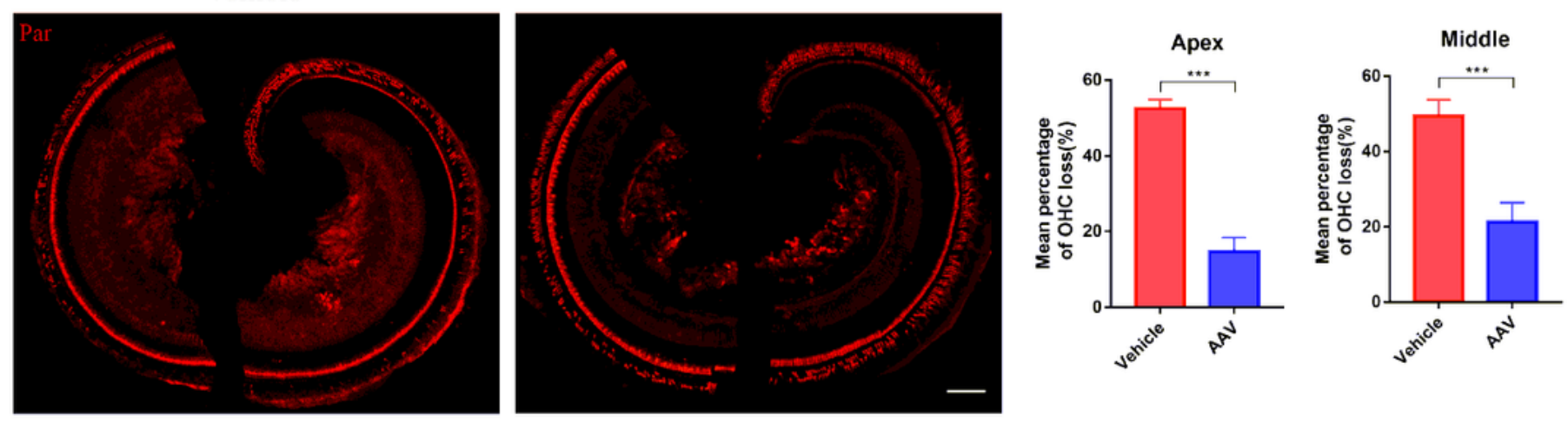

Figure 7 
AAV therapy resulted in some degree of phenotypic recovery (A) Representative confocal images of the basilar membrane in Klc2-null mice at P14, with parvalbumin (red) labeling the HCs and HA-tag (green) labeling Klc2-HA. Klc2 was reexpressed in both the nuclei and cytoplasm of HCs, $n=3$. Scale bar: $20 \mu \mathrm{m}$. (B) Protein was extracted from the cochlea and cerebellum at P14, and Western blot using anti-Klc2 and anti-HA antibody was performed to verify the reexpression of Klc2, indicating that Klc2 was only reexpressed in the cochlea of the AAV group, $n=4$. (C) The ABR threshold gap narrowed at P40 after AAV therapy, $n=6,{ }^{* *} p<0.001$ for $4 \mathrm{kHz}$ and $8 \mathrm{kHz}$, ${ }^{*} p<0.05$ for $12 \mathrm{kHz}$. (D) The HCs of the apical and middle turns of the basilar membrane of the "AAV group" and "Vehicle group" were immunostained with parvalbumin (green) at P40, and loss of OHCs was significantly decreased in the "AAV group", $n=3$. Scale bar: $100 \mu \mathrm{m} . * * * \mathrm{p}<0.001$.

\section{Supplementary Files}

This is a list of supplementary files associated with this preprint. Click to download.

- SupplementalData.docx 